$\xi=-1$

\title{
Determination of Optimum Machining Condition for Surface Roughness Using Historical Data
}

\author{
Mohd Shahfizal Mohd Ruslan ${ }^{1,2 *}$, Haniff Abdul Rahman ${ }^{1}$, Jaharah Abdul Ghani ${ }^{1}$, Che Hassan Che Haron ${ }^{1}$, Mohd \\ Shahir Kassim ${ }^{3}$, Kamal Othman ${ }^{1,2}$
}

${ }^{1}$ Centre of Materials Engineering and Smart Manufacturing (MERCU), Universiti Kebangsaan Malaysia

${ }^{2}$ Production Technology Department, German Malaysian Institute

${ }^{3}$ Department of Process, Universiti Teknikal Malaysia Melaka

*Corresponding author E-mail: mohdshahfizal@gmail.com

\begin{abstract}
Magnesium alloy is one of the lightest materials with a high strength to weight ratio and excellent machinability, which makes it attractive and suitable for various industrial applications such as automotive and aerospace components. For these particular industrial components, the end products require a mirror-like finish. This article details a statistical analysis about the effect of milling parameters on the surface roughness of Magnesium alloy AZ91D in the dry milling process. The historical data approach in the response surface methodology (RSM) was utilized to determine the cause and effect relationship between the input variables and output response. The effect of milling parameter studied was cutting speed $(900-1400 \mathrm{~m} / \mathrm{min})$, feed rate $(0.03-0.09 \mathrm{~mm} / \mathrm{tooth})$, and radial depth of cut $(0.2-0.3 \mathrm{~mm})$. The results confirmed that the interaction between feed rate and cutting speed is the primary factor controlling the surface evolution. The responses of various factors were plotted using a two-dimensional interaction graph and the cubic empirical model was developed at 95\% confidence level. The optimum condition for achieving the minimum surface roughness was a cutting speed of $977 \mathrm{~m} / \mathrm{min}$, a feed rate of $0.02 \mathrm{~mm} /$ tooth, and an axial depth of cut of $0.29 \mathrm{~mm}$. With this optimum condition, a surface arithmetic roughness of $0.054 \mu \mathrm{m}$ is expected. This study confirmed that by milling AZ91D at high speed cutting, it is possible to eliminate the polishing process to achieve a super mirror-like finishing.
\end{abstract}

Keywords: AZ91D; Dry Cutting; High Speed Machining; Historical Data; Optimize; Response Surface Method; Surface Roughness.

\section{Introduction}

Current interest is focused on the growing demand for more fuelefficient vehicles that reduces energy consumption and air pollution. Addressing this concern is becoming an ongoing challenge for the automotive industry. Magnesium alloy is one of the lightest materials, and it is rapidly gaining acceptance in various applications, such as in the automotive, aerospace, electronics, industrial biomedical, and sports industries. Due to its lightness and durability, there is an increase in the usage of magnesium in the automotive industry alongside the advancement in new frontier technology [1]. Considering the more stringent requirements for improved fuel economy and emissions, substituting aluminium and magnesium for conventional steel and cast iron is a growing trend in vehicle manufacturing [2].

Magnesium alloys are known for its excellent physical and mechanical properties, such as low density, very high strength to weight ratio, high stiffness, and mechanical cast ability. They are preferred over aluminium or steel alloys in the automotive industry due to its promising high strength to weight ratio. Unfortunately, the poor corrosion resistance of magnesium alloy has limited its practical applications. Nevertheless, it is largely utilized in the automotive industry due to its advantage in terms of energy and environmental concerns. Recently, leading car manufacturers are investigating the replacement of steel with lighter materials, such as magnesium, to achieve lightweight construction without sacri- ficing rigidity. This can consequently lead to greenhouse gas reductions and limit the amount of exhaust emissions, both of which satisfy legislative and consumers' requirements for safer and cleaner vehicles [3]. Despite the growing interest in magnesium alloys, very little data exist on the wear behaviour of the tool after the machining process and the influence of cutting fluid during the machining process.

Most lightweight materials, such as magnesium, are widely used in the automotive and truck manufacturing industries [4]. Weighing $~ 30 \%$ lighter than aluminium and $60 \%$ lighter than steel, magnesium proved that it is the lightest structural metal [5]. Magnesium alloys offer an excellent combination of mechanical and physical properties, such as high specific strength, high damping capacity, good cast ability, and excellent electromagnetic shielding properties. In terms of fuel efficiency and for economic reasons, magnesium alloy is the best choice, since it has a relatively low density compared to other materials [6]. However, magnesium alloy exhibited poor machining at low temperatures due to its hexagonal closed-packed crystal structure, consequently requiring it to be processed at elevated temperatures. Its high affinity with oxygen leads to easy oxidation [7]. AZ91D alloy is the most common die-casting alloy used in more than $90 \%$ of all magnesium die cast products [8]. Although this alloy has a good combination of mechanical properties, die cast ability, and corrosion resistance, it has poor creep resistance. It starts to creep at temperatures above $100^{\circ} \mathrm{C}$, and has a maximum operating temperature of $125{ }^{\circ} \mathrm{C}$ [9]. According to [10], in spite of its lower fatigue strength, AZ91 has made significant inroads in non-structural and 
low-temperature components, such as brackets, covers, cases, and oil pump housings.

Magnesium is the fastest machining metal and it has a high thermal conductivity. Advantages of it include long tool life, the tool stays sharp for long time, low power consumption at $\sim 55 \%$ lower than that of aluminium alloys, reduction of machining time due to high speeds, short chips, and an excellent surface. The cutting energy for machining of magnesium is lower than that for other materials

Hou et al. [11] stated that when magnesium alloy is machined at high cutting speeds, thin and light chips are generated. These chips are prone to igniting due to its low heat capacity and high thermal expansion [11]. Moreover, when the cutting speed start to exceed the critical value, build up edges might be produced, resulting in serious adverse effect to the surface quality of the component [12]. Currently, there are not many researches on the effect of cutting parameter and cutting condition under cryogenic conditions toward surface quality of machining magnesium alloy.

This article details a statistical analysis of the factors affecting the surface roughness of mirror-like finishing when machining AZ91D at high cutting speeds. We will show that the interaction between feed rate and cutting speed is the primary factor that controls the surface evolution.

\section{Material and Methods}

In this study, the magnesium alloy AZ91D was provided by Sell Well Industries Group Ltd. The dimension of the work piece was $150 \mathrm{~mm}$ in length, $150 \mathrm{~mm}$ wide, and $50 \mathrm{~mm}$ high. The chemical composition of this material is shown in Table 1. Prior to the experiment, the work piece was pre milled to remove its original skin layer, which contain hard particles such as oxide and carbides. The cutting tool that was used is WALTER SDGT 09T3AEN-G 88, with a diameter of $50 \mathrm{~mm}$ and a $45^{\circ}$ approach angle. Its chemical composition is shown in Table 2 . The cutting tool holder Walter F2233.B.050.204.05 was used to mount the cutting tool.

Table 1: Chemical composition of work material of AZ91D in wt\%

\begin{tabular}{|c|c|c|c|c|c|c|}
\hline \multicolumn{7}{|c|}{ Chemical composition (\%) } \\
\hline $\mathrm{Al}$ & $\mathrm{Zn}$ & $\mathrm{Mn}$ & $\mathrm{Fe}$ & $\mathrm{Si}$ & $\mathrm{Cu}$ & $\mathrm{Ni}$ \\
\hline & & & & & & \\
\hline 8.73 & 0.65 & 0.2 & 0.0028 & 0.012 & 0.0019 & 0.0004 \\
\hline
\end{tabular}

Table 2: Chemical composition of carbide cutting tool

\begin{tabular}{|c|c|c|c|c|c|c|c|}
\hline \multicolumn{7}{|c|}{ Chemical composition (\%) } & \\
\hline WC & $\mathrm{TiC}$ & $\mathrm{TaC}$ & $\mathrm{Cr} 3 \mathrm{C} 2$ & $\mathrm{Co}$ & $\mathrm{Ni}$ & ISO Grade & \\
\hline 92. & - & 1.0 & 0.3 & 6.0 & - & $\mathrm{N}(\mathrm{K} 10)$ & \\
\hline
\end{tabular}

The experiment was performed using a high speed CNC milling Spinner VC450 Machining Centre, with a capacity of $5.6 \mathrm{~kW}$ of power and $23 \mathrm{Nm}$ torque. The machining was carried out in dry condition. Seventy two sets of experiments were conducted, which were then analyzed using historical data of RSM. The factors and levels for the experimental runs is tabulated in Table 3. The levels of cutting speed $(\mathrm{Vc})$, feed rate (fz) and axial depth of cut (ap) used in the experiment were in the high speed regime of machining for magnesium alloy. Furthermore, its range of cutting speed $(\mathrm{Vc})$ of $900-1400 \mathrm{~m} / \mathrm{min}$, its feed rate of $0.03-0.09$ $\mathrm{mm} / \mathrm{tooth}$, and its axial depth of cut (ap) of 0.2-0.3 mm are suitable for the finishing process. The challenge in cutting the magnesium alloy at a very small depth of cut was due to the spark(s) generated during machining.

A Mitutoyo Surftest SJ-310 surface roughness tester was used for measuring the roughness values of the machined surface. The stylus traversing length, Lt, was set to $5.4 \mathrm{~mm}$ with a cut off, c, at $0.8 \mathrm{~mm}$. Measurements were taken parallel to the milling feed direction. The total measurements were taken after the milling was performed and repeated 5 times to obtain its average and standard deviation values.
Table 3: Experimental factor and their levels

\begin{tabular}{|l|c|c|c|}
\hline Factor/Level & -1 & 0 & 1 \\
\hline $\begin{array}{l}\text { Cutting Speed, Vc, } \\
(\mathrm{m} / \mathrm{min})\end{array}$ & 900 & 1100 & 1400 \\
\hline Feed, fz, (mm/tooth) & 0.03 & 0.06 & 0.09 \\
\hline Axial depth, ap, (mm) & 0.2 & 0.25 & 0.3 \\
\hline
\end{tabular}

The experiment was performed with 72 sets of data collected during machining and analyzed using a statistical method. The statistical method being used for this experiment are the historical data with four factor and three level designed by Design Expert 6.0 software. In order to determine the factors affecting the surface roughness, an analysis of variance (ANOVA) and optimization using historical data option in response surface method (RSM) were performed on the experimental results contributed by the surface roughness evolution.

\section{Results and discussion}

\subsection{Surface roughness}

The Ra values for surface roughness measured were in the range of $0.057-0.393 \mu \mathrm{m}$ for all of the 72 experimental runs, i.e. less than $0.5 \mu \mathrm{m}$, which is equivalent to manual polishing [13]. The suggestion optimized results from the 72 set of historical data, suggesting 10 sets of optimized parameters that needs to be validate by running back the suggested parameter for Table 4 . The measured surface roughness ( $\mathrm{Ra}$ ) value at the beginning of cutting in dry conditions are shown in Table 4. It can be seen that using this range of cutting conditions, a mirror like surface roughness in the range of 0.05- $0.08 \mu \mathrm{m}$ were achieved. The lowest differences in terms of percentage is optimized to run number 7, with an Ra of $0.067 \mu \mathrm{m}$ for actual and $0.069 \mu \mathrm{m}$ were produced in dry condition at $2.9 \%$ of difference surface roughness $(\mathrm{Ra})$ by cutting parameter of cutting speed of $1300 \mathrm{~m} / \mathrm{min}$, feed rate of $0.02 \mathrm{~mm} /$ tooth, and depth of cut of $0.2 \mathrm{~mm}$. The highest Ra difference in percentage were achieved under dry condition and a cutting speed of $1300 \mathrm{~m} / \mathrm{min}$, a feed rate of $0.05 \mathrm{~mm} / \mathrm{tooth}$, and a depth of cut of 0.3 $\mathrm{mm}$.

Table 4: Validation of Optimized Parameters

\begin{tabular}{|c|c|c|}
\hline $\begin{array}{c}\text { Response actual } \\
\text { surface roughness } \\
(\mathrm{Ra})\end{array}$ & Solution suggestion & Diff in \% \\
\hline 0.086 & 0.059 & 45.8 \\
\hline 0.065 & 0.06 & 8.3 \\
\hline 0.092 & 0.061 & 50.8 \\
\hline 0.084 & 0.061 & 37.7 \\
\hline 0.080 & 0.063 & 27.0 \\
\hline 0.067 & 0.064 & 4.7 \\
\hline 0.067 & 0.069 & -2.9 \\
\hline 0.094 & 0.07 & 34.3 \\
\hline 0.062 & 0.073 & -15.1 \\
\hline 0.074 & 0.077 & -3.9 \\
\hline
\end{tabular}

The experiment was performed with 72 sets of data collected during machining and analyzed using a statistical method. The statistical method being used for this experiment are the historical data with four factor and three level designed by Design Expert 6.0 software. In order to determine the factors affecting the surface roughness, an analysis of variance (ANOVA) and optimization using historical data option in response surface method (RSM) were performed on the experimental results contributed by the surface roughness evolution.

\subsection{Analysis of variance (ANOVA)}

The progression of the resultant force starts from the beginning of the cut until the tool flank wear. The 72 sets of data were then analyzed using historical data and RSM in the Design Expert 6 software. The analysis revealed that all of the experiment results 
are significant for model terms. These terms were sorted according to the F-value, and showed that excellent surface finish cannot be achieved by a single factor. The surface roughness achieved in the analysis was due to the interaction between factors resulted in the surface roughness, ranged from $0.173-0.3 \mu \mathrm{m}$ i.e. within the range of actual surface roughness measured. The analysis also showed that 5 interactions with $\mathrm{P}$-values less than 0.05 , i.e. these interactions are significant to the surface roughness.

Based on the analysis of variance (ANOVA) in Table 5, the cubic model was found to be significant, with a confident level of $95 \%$. The cutting parameter with a P-Value of less than 0.05 is considered a significant effect to the response (surface roughness). Based on this analysis, it was found that the most significant factor affecting the surface roughness was the feed rate. The cubic model also indicates that the surface finish was not solely affected by one factor.

Table 5 ANOVA table for surface finish reduced cubic model

\begin{tabular}{|c|c|c|c|c|c|c|}
\hline Source & $\begin{array}{l}\text { Sum of } \\
\text { Squares }\end{array}$ & $\begin{array}{l}D \\
F \\
\end{array}$ & $\begin{array}{c}\text { Mean } \\
\text { Square }\end{array}$ & $\begin{array}{c}F- \\
\text { Value }\end{array}$ & $\begin{array}{l}\text { Prob } \\
>F \\
\end{array}$ & \\
\hline Model & 0.157257 & 9 & 0.017473 & $\begin{array}{c}60.26 \\
072\end{array}$ & $\begin{array}{c}< \\
0.000 \\
1\end{array}$ & $\begin{array}{l}\text { signifi- } \\
\text { cant }\end{array}$ \\
\hline$V c$ & 0.001015 & 1 & 0.001015 & $\begin{array}{c}3.501 \\
387\end{array}$ & $\begin{array}{c}0.066 \\
3\end{array}$ & \\
\hline$f z$ & 0.000978 & 1 & 0.000978 & $\begin{array}{c}3.372 \\
003\end{array}$ & $\begin{array}{c}0.071 \\
4\end{array}$ & \\
\hline$a p$ & $4.62 \mathrm{E}-05$ & 1 & $4.62 \mathrm{E}-05$ & $\begin{array}{c}0.159 \\
312 \\
\end{array}$ & $\begin{array}{c}0.691 \\
2 \\
\end{array}$ & \\
\hline$f z^{2}$ & 0.034972 & 1 & 0.034972 & $\begin{array}{c}120.6 \\
104\end{array}$ & $\begin{array}{c}< \\
0.000 \\
1\end{array}$ & \\
\hline$V c . f z$ & 0.004626 & 1 & 0.004626 & $\begin{array}{c}15.95 \\
285\end{array}$ & $\begin{array}{c}0.000 \\
2\end{array}$ & \\
\hline Vc.ap & 0.002413 & 1 & 0.002413 & $\begin{array}{c}8.320 \\
378 \\
\end{array}$ & $\begin{array}{c}0.005 \\
5\end{array}$ & \\
\hline Fz.ap & 0.000536 & 1 & 0.000536 & $\begin{array}{c}1.847 \\
904 \\
\end{array}$ & $\begin{array}{c}0.179 \\
2 \\
\end{array}$ & \\
\hline$f z^{3}$ & 0.010683 & 1 & 0.010683 & $\begin{array}{c}36.84 \\
231\end{array}$ & $\begin{array}{c}< \\
0.000 \\
1\end{array}$ & \\
\hline $\begin{array}{c}V c . f z . a \\
p\end{array}$ & 0.002034 & 1 & 0.002034 & $\begin{array}{c}7.013 \\
12\end{array}$ & $\begin{array}{c}0.010 \\
4\end{array}$ & \\
\hline $\begin{array}{c}\text { Resid- } \\
\text { ual }\end{array}$ & 0.017107 & $\begin{array}{l}5 \\
9 \\
\end{array}$ & 0.00029 & & & \\
\hline $\begin{array}{c}\text { Lack of } \\
\text { Fit }\end{array}$ & 0.013362 & $\begin{array}{l}4 \\
9 \\
\end{array}$ & 0.000273 & $\begin{array}{c}0.728 \\
055 \\
\end{array}$ & $\begin{array}{c}0.779 \\
5 \\
\end{array}$ & $\begin{array}{c}\text { not signif- } \\
\text { icant }\end{array}$ \\
\hline $\begin{array}{l}\text { Pure } \\
\text { Error }\end{array}$ & 0.003746 & $\begin{array}{l}1 \\
0\end{array}$ & 0.000375 & & & \\
\hline $\begin{array}{c}\text { Cor } \\
\text { Total }\end{array}$ & 0.174365 & $\begin{array}{l}6 \\
8\end{array}$ & & & & \\
\hline
\end{tabular}

$R a=0.2938 x-0.0002 V c x-0.20 f z x-1.45$ apx $-36.91 f z 2 \times 0.004$ vc.fz $\times 0.0012$ Vc.ap $\times 22.81$ fz.ap $x 170.45 f z 3 x-0.018$ Vc.fz.ap

\subsection{Response surface for the interaction effect between parameters}

The interaction effect of cutting speed and feed rate is shown in Figure 1. The graph shows that surface roughness is high at slow cutting speeds and higher feed rates. However, this phenomenon is contradicted at low feed rates. It was noticed that the Ra value will not change significantly with increased cutting speed.
DESIGN-EXPERT PIot Surface finish (Ra)

$X=A: V_{0}$
$Y=B: t z$

- Design Points

- $\mathrm{B}-0.020$

$\Delta \mathrm{B}+0.180$

Actual Factor

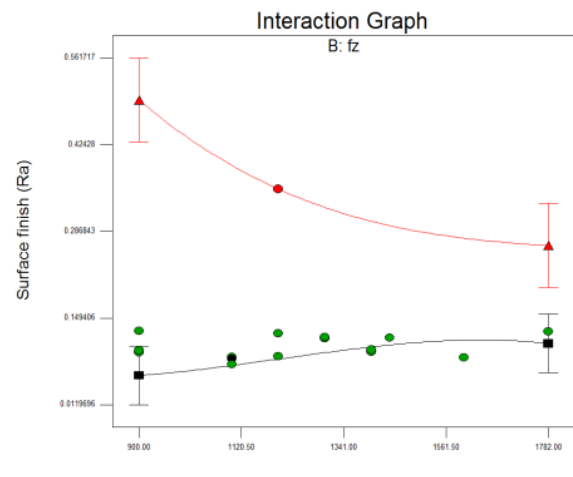

A: Vc

Fig. 1: Response surface for the interaction effect between cutting speed and feed rate

Figure 2 shows the non-significant interaction of depth of cut and cutting speed. It was observed that changing cutting speed does not affect the surface finish for both depth of cut of 0.2 and 0.4 $\mathrm{mm}$ respectively. However, $\mathrm{Ra}$ is slightly higher during low speed at a $0.4 \mathrm{~mm}$ depth of cut.

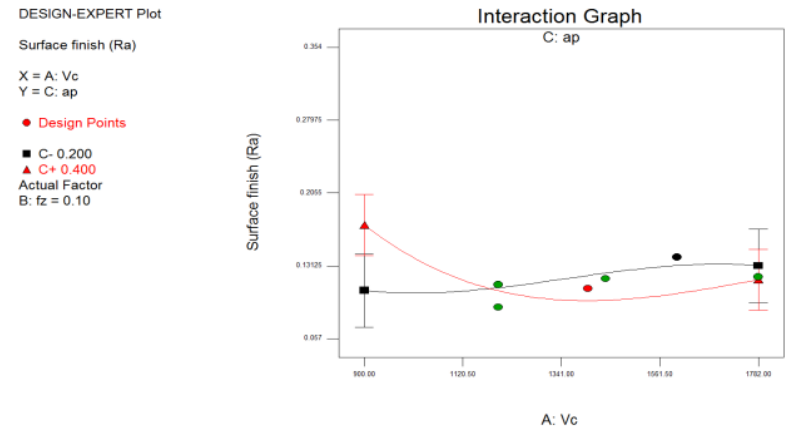

Fig. 2: Interaction effect between depth of cut and cutting speed

Figure 3 shows the interaction graph between the depth of cut and feed rate. The effect at depth of cuts of 0.2 and $0.4 \mathrm{~mm}$ is similar at different values of feed rate. Different values of feed rate will not affect the surface roughness when the feed rate value is below the mid-range of the feed rate value. However, it can drastically deteriorate surface roughness when the feed rate is more than 0.12 $\mathrm{mm} /$ tooth, as shown by the steepest curvature line. Kim [14] researched the magnesium alloy AZ31D using dry milling, and found that surface roughness increases with increasing feed-rate per tooth and increasing number of inserts in the cutting tool.

DESIGN-EXPERT Plot
Surface finish (Ra)
$X=B:$ fz
$Y==$ : ap
- C. 0.200
Act 0.400
Actual Factor
A: $V c=1341.00$

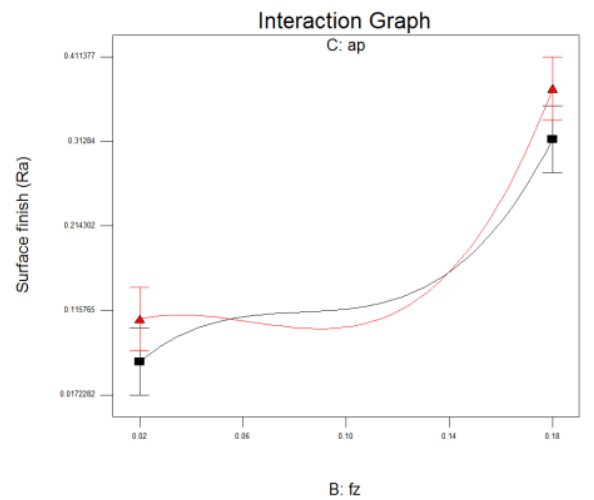

Fig. 3 Interaction effect between depth of cut and feed rate

Figure 4 shows the contour graph of optimization solutions based on the objective to obtain minimum surface roughness. It can be seen that the best surface finish of $0.054 \mu \mathrm{m}$ can be achieved via the combination of $\mathrm{Vc}=977 \mathrm{~m} / \mathrm{min}, \mathrm{fz}=0.02 \mathrm{~mm} / \mathrm{tooth}$, and ap $=$ 0.29 . 


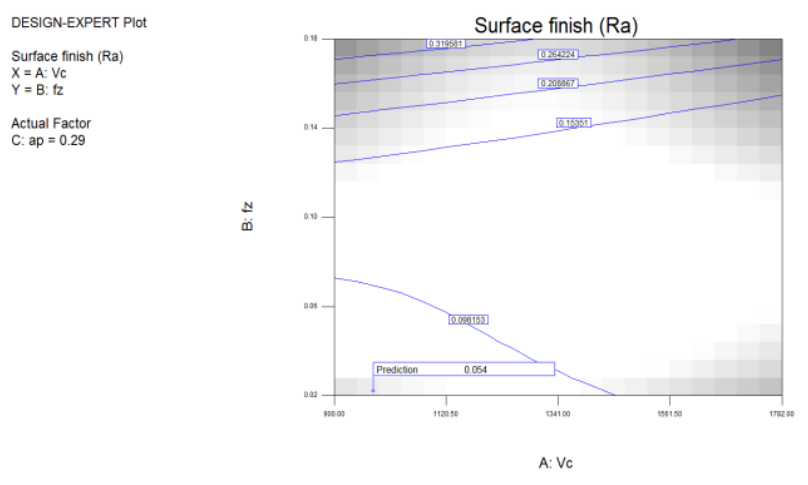

Fig. 4 Optimization cutting parameter to obtain minimum surface roughness

Figure 5 shows the spark observed for certain experimental runs. However, in most cases, the spark was not present. In previous studies, a high depth of cut was used to avoid the occurrence of sparks when machining magnesium alloy [15], since the chip formed needs to be kept large to reduce any fire hazard potential and avoid damaging the machine tool components by polluting sensitive areas under dry machining conditions.

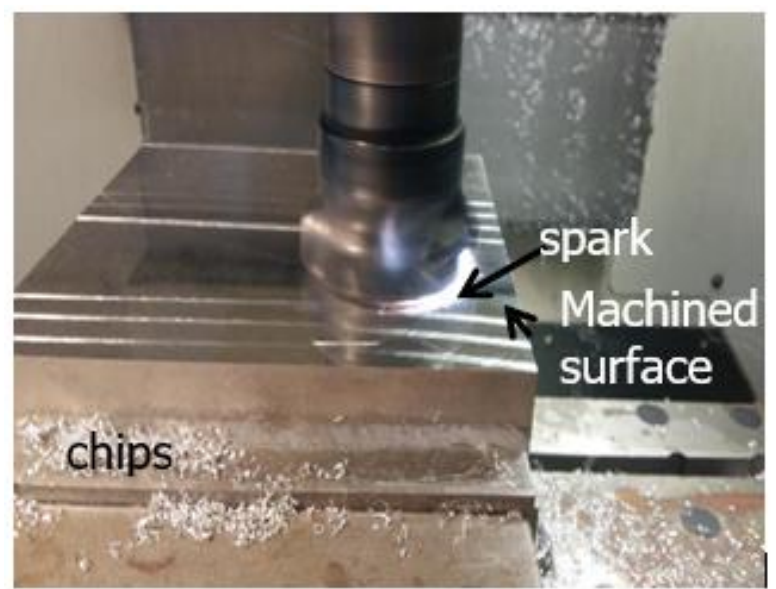

Fig. 5: Fire spark that was observed in machining of AZ91D

\section{Conclusion}

From the study conducted, it was found that excellent surface roughness was achieved in the range of $0.057-0.393 \mu \mathrm{m}$, which is less than $0.5 \mu \mathrm{m}$, and can be obtained by manual polishing. Furthermore, the surface roughness achieved using historical data RSM analysis ranged from $0.173-0.3 \mu \mathrm{m}$, which was due to the interaction between factors. Single factors are not significant. The predicted optimum condition for achieving the minimum surface roughness was a cutting speed of $977 \mathrm{~m} / \mathrm{min}$, a feed rate of 0.02 $\mathrm{mm} /$ tooth, and an axial depth of cut of $0.29 \mathrm{~mm}$. The analysis also found that the Ra value will not change significantly with increases in cutting speeds and depths of cut.

\section{Acknowledgement}

The authors would like to thank the Government of Malaysia and Universiti Kebangsaan Malaysia for their financial support under FRGS/1/2016/TK03/UKM /01 /1 and GUP-2017-048 grants.

\section{References}

[1] Buldum B, Sik A \& Ozkul (2013), Investigation of Magnesium Alloys Machinability. International Journal of Electronics, Mechanical and Mechatronics Engineering 2(3), pp. 261-268.
[2] Cole GS \& Sherman AM (1995), Lightweight Materials for Automotive Applications. Journal of Automative Application 35(1), pp. 3-9.

[3] Song, Guangling, Amanda LB \& David HSJ (2014), Corrosion resistance of aged die cast magnesium alloy AZ91D. Materials Science and Engineering: A 366.1, pp. 74-86.

[4] Mabuchi M, Nakamura M, Ameyama K, Iwasaki H \& Higashi K (1999), Superplastic Behavior of Magnesium Alloy Processed by ECAE. Mater. Sci. Forum 304-306, pp. 67-72.

[5] Steve Robison (2012), Introduction to the Magnesium Casting Industry. American Foundry Society, Schaumburg, IL. Technical information of aluminium alloy, Homepage http://www.aalco.co.uk.

[6] Baptista R \& Antune Simões JF (2000), Three and five axes. Journal of Materials Processing Technology 103, pp. 398-403.

[7] Mohd Ruzi H, Norhamidi M, Abu Bakar S, Khairur RJ, Nor Hafiez MN, Sufizar A, Mohd Halim \& Murtadhahadi II (2011), A Review of Workability of Wrought Magnesium Alloys, Advanced Manufacturing, Research Group'09 Seminar 3.

[8] Garmo EPD, Black JT \& Kohser RA (1997). Magnesium and magnesium alloys. Materials and processes in manufacturing (8th Edition). Wiley, USA, pp. 182-184.

[9] Nakaura Y, Watanabe A \& Ohori K (2006), Effects of Ca, Sr Additions on Properties of Mg-Al Based Alloys. Materials Transactions 47(4), pp. 1031-1039.

[10] Musfirah AH \& Jaharah AG (2012), Magnesium and Aluminium Alloys in Automotive Industry. Journal of Applied Sciences Research 8(9), pp 4865-4875.

[11] Hou, Junzhan, Ning Zhao \& Shaoli Zhu. (2011), Influence of cutting speed on flank temperature during face milling of magnesium alloy. Materials and Manufacturing Processes 26(8), pp. 10591063.

[12] Tomac, Nikola KT \& Finn OR (1991), Formation of flank build-up in cutting magnesium alloys. CIRP Annals-Manufacturing Technology 40(1), pp. 79-82.

[13] Davies G (2003), Magnesium Materials for automotive bodies, Elsevier, G. London, pp. 91, 158, 159.

[14] Kim JD (2010), Surface Roughness Evaluation in Dry-Cutting of Magnesium Alloy by Air Pressure Coolant. Engineering 02(10), pp. 788-792. doi:10.4236/eng.2010.210101.

[15] Tönshoff HK \& Winkler J (1997), The Influence of Tool Coatings in Machining of Magnesium. Surface and Coatings Technology 9495, pp. 610-616. 